\title{
Can Mediterranean terroirs withstand climate change? Case studies at the Alentejo Portuguese winegrowing region
}

\author{
Carlos M. Lopes ${ }^{1 \mathrm{a}}$; Joaquim M. Costa ${ }^{1}$, Ricardo Egipto ${ }^{1}$, Olfa Zarrouk $^{2}$ and Maria M. Chaves ${ }^{2}$ \\ ${ }^{1}$ LEAF, Linking Landscape, Environment, Agriculture and Food, Instituto Superior de Agronomia, Universidade de \\ Lisboa, Tapada da Ajuda 1349-017 Lisboa, Portugal, email: carlosmlopes@isa.ulisboa.pt. \\ ${ }^{2}$ LEM, ITQB-NOVA, Univ. Nova de Lisboa, Apartado 127, 2780-901 Oeiras, Portugal.
}

\begin{abstract}
Climate change introduced new challenges to vinegrowers in the Mediterranean areas such as the hot and dry winegrowing region of Alentejo, south Portugal. Warmer and drier conditions are harmful for grape yield and berry quality attributes and for vine's longevity, mainly when optimal thresholds are exceeded. Therefore winegrowers are forced to move from rainfed to irrigated production systems making Alentejo' wine production strongly based on available water resources for irrigation. This work aims to review and discuss ecophysiological and agronomical data obtained in irrigation trials set up at different terroirs of Alentejo. In the last four decades, classical bioclimatic temperature-based indices showed a significantly positive trend, while the dryness index present a negative trend over time. Furthermore, ecophysiological data collected in deficit irrigation experiments are reviewed and discussed, focusing on the effects of drought and heat stress on vigour, yield and berry composition. Emphasis is given on the indirect effects of leaf senescence on cluster exposure and consequences on berry temperature and composition. In order to promote the sustainability and quality of wine production in these hot and dry terroirs short- to longterm adaptation measures are suggested. The limitations and risks of using deficit irrigation during heat waves are also underlined.
\end{abstract}

\section{Introduction}

The incidence of drought have increased in recent years and, according to model predictions for future climate in South Mediterranean Europe, it is expected an increase in winter rains and an extended summer drought, coupled to a substantial increase in temperature $[1,2]$. Consequently, water demand will increase and soil water balance during the grapevine vegetative period will become more negative [3]. Furthermore, climatic scenarios predict that heat waves tend to strike the Mediterranean region more frequently and for longer periods $[4,5]$. All these changes pose new challenges to vinegrowers in the Mediterranean areas such as the hot and dry winegrowing region of Alentejo, south Portugal.

The predicted higher air temperatures and less precipitation during the grapevine growing season, and mainly during the ripening period, were already observed in Portugal in recent decades [2, 6, 7]. In Alentejo's winegrowing region the vineyard surface area has experienced a fast expansion during the last decades of the XX century attaining in 2016 about 23,400 ha [8], most of them drip irrigated.

Water stress and supra-optimal temperatures are known to decrease plant carbon assimilation, to reduce vegetative growth and yield and to affect berry composition [9] and, in extreme cases, could also affect vine's longevity. In order to overcome the negative impact of climatic changes on grape yield and composition and vine's longevity, Alentejo's grape growers have been forced to move from rainfed to irrigated production systems and nowadays all the new vineyards are planted with a drip irrigation system, making Alentejo' wine production strongly based on available water resources for irrigation. Despite the recent building of the "Alqueva" big dam, water in Alentejo is 
still a scarce resource forcing the grape growers to use water more efficiently.

In those regions, deficit irrigation strategies such as sustainable and regulated deficit irrigation have been successfully adopted as management tools to control vine vegetative growth and improve fruit composition, while enhancing plant water use efficiency [10 - 12]. However, deficit irrigation induces progressive increase in water stress along the growing season [13, 14], which can promote early leaf senescence and leaf fall at the fruiting zone $[8,15]$. Furthermore, in case of heat waves, due to the restriction in stomatal conductance and consequent decrease in the ability to energy dissipation, supraoptimal canopy temperatures are attained and vine vulnerability to leaf burning increased [16]. The resultant defoliation increases cluster sun exposure, leading to berry sunburn and/or to abnormal ripening, producing reduced yield, juice with low titratable acidity and a loss of aromatic compounds [17, 18]. In red varieties, the high temperature that the fully exposed berries can achieve may also affect anthocyanin concentration either through degradation, inhibition of synthesis, or, more likely, both [19 - 20].

In this context, we aimed to review and discuss ecophysiological and agronomical data obtained in two vineyard irrigation experiments conducted at different terroirs of the hot and dry region of Alentejo, south of Portugal. Furthermore, short- to long-term adaptation measures are suggested.

\section{Material and Methods}

Two independent field experiments were carried out at two PDO sub-regions of Alentejo, South Portugal: Évora and Reguengos. The Évora field trial was carried out in 1999 at a commercial vineyard located nearby the city of Évora. The fourteen-year-old grapevines of the red variety 'Aragonez' syn. 'Tempranillo', grafted on 1103P rootstock, were spaced $2.5 \mathrm{~m}$ between and $1.1 \mathrm{~m}$ along North-South oriented rows and trained on a vertical trellis. The soil is an Antrossoil with an ApCR profile derived from granite with $75 \%$ of sand and high percentage of gross elements. The experiment was set up in a randomized block design with four replicates per treatment. Two deficit irrigation strategies (DIv- 50\% ETc withheld after veraison and DIh - 50\% ETc supplied until harvest), were tested against a non-irrigated control (NI). Irrigation started at the end of May (10 days after full bloom) and was cut-off at the end of July (veraison) for the DIv treatment and one week before harvest (end of August) for DIh one. A total of 144 and $216 \mathrm{~mm}$ was applied once a week in DIv and DIh respectively. More detailed information could be obtained in [15].

The second irrigation trial took place in 2013 at a commercial vineyard located near Reguengos de Monsaraz. The eleven years-old grapevines of the variety 'Aragonez', grafted to 1103 Paulsen rootstock were spaced $1.5 \mathrm{~m}$ within and $3.0 \mathrm{~m}$ between north-south oriented rows. Vines were trained on a vertical shoot positioning system with one pair of movable wires and spur-pruned on a bilateral Royat Cordon system with 16 nodes per vine. Soil texture is a sandy-loam to silty-clayloam, with a $\mathrm{pH}$ of 7.0 to 7.6 and low organic matter content. The experimental layout is a randomized complete block design with two irrigation treatments (Sustainable Deficit Irrigation (SDI -control; 30\% ETc) and Regulated Deficit Irrigation (RDI; $\sim 15 \%$ ETc), and 4 replications per treatment. For more details check [21, 26].

Soil and plant assessments were similar in the two experiments. Soil water content was monitored with a neutron probe (Évora) or a capacitance probe (Reguengos) in 4 access tubes per treatment installed in the row between two contiguous vines with readings taken periodically at increments of $0.2 \mathrm{~m}$ (Évora) or 0.1 $\mathrm{m}$ (Reguengos) from soil surface to a depth of $c a 1.0 \mathrm{~m}$. The fraction of transpirable soil water was calculated according to [22]. Predawn and midday leaf water potential were measured in fully mature and well-exposed leaves per treatment, on the day before irrigation, using a pressure chamber. Diurnal curves of leaf gas exchange were done along the season with a portable infrared gas analyser (LI-6400, Li-Cor Inc., USA) in 4-6 fully mature , sunlit leaves per treatment. Light at the cluster zone was measured on sunny days at midday using a Sunflek Ceptometer inserted horizontally at the cluster zone along the row. Incident active radiation (PAR) was expressed in percentage of a reference PAR, measured over the canopy top. Berry temperature was monitored continuously with a dual channel temperature data logger with a twojunction fine wires copper-constantan thermocouples attached. These probes were positioned on berry surface of a sample of clusters located in different canopy positions (exposed east and west) of 2 vines per treatment. Cluster number and weight per vine were assessed at harvest and one berry sample per replication was collected to evaluate berry composition. Pruning weight and shoot number per vine were also recorded.

\section{Results and Discussion}

\subsection{Pattern of bioclimatic indices in the last decades}

As shown in Fig. 1A, the temperature-based Huglin index calculated for the last four decades presented a significantly positive trend over years, changing from the warm temperate class to warm and very warm classes [23]. In turn, the dryness index, which is an index based on the potential soil water balance calculated in the budburst-harvest period, shows a negative trend over years with most part of the seasons classified within the very dry class [24] (Fig. 1B).

\subsection{Rainfed vs deficit irrigation at Évora}


Figure 2A presents the seasonal trend of the fraction of transpirable soil water (FTSW) measured in the $0-1.0 \mathrm{~m}$ soil profile at the end of each irrigation cycle. The soil was almost fully refilled in winter/early spring but, after March the FTSW started a decreasing pattern till the end of the growing cycle. At the start of irrigation (end of May) all treatments presented a similar FTSW ( ca 60\%). However, in June and July (flowering to veraison) the NI treatment showed a faster decrease in FTSW, presenting significantly lower values than the two deficit irrigated treatments. During the ripening phase, the two deficit irrigation continued the decreasing pattern, attaining harvest with very low FTSW, similar to that of the NI treatment.

Regarding plant water status, the predawn leaf water potential $\left(\Psi_{\mathrm{pd}}\right)$ presented a parallel decreasing pattern as that described for FTSW (Fig. 2B). In NI vines $\Psi_{\mathrm{pd}}$ attained very low values at veraison $(c a-0.9 \mathrm{MPa})$ and values lower than -1.0 MPa during ripening, indicative of severe water stress. In the deficit irrigation treatments $\Psi_{\mathrm{pd}}$ presented a similar decreasing trend until veraison, but the values attained were higher than those of NI. After arresting irrigation at veraison DIv showed a steeper $\Psi_{\mathrm{pd}}$ decrease than DIh vines, attaining at harvest values close to those of NI plants and lower than those of the DIh. The midday leaf water potential $\left(\Psi_{\mathrm{m}}\right)$ showed also a decreasing pattern along the season. However the relative differences between treatments were less pronounced than in $\Psi_{\mathrm{pd}}$ (Fig. 2B). The seasonal variation of midday stomatal conductance (gs) mirrors that reported for $\Psi_{\mathrm{pd}}$ but with a stronger reduction before veraison. After irrigation suspension on the DIv, the gs showed a strong decline, achieving at harvest significantly lower values than those of the DIh vines but similar to those of the NI ones (Fig. 2C).
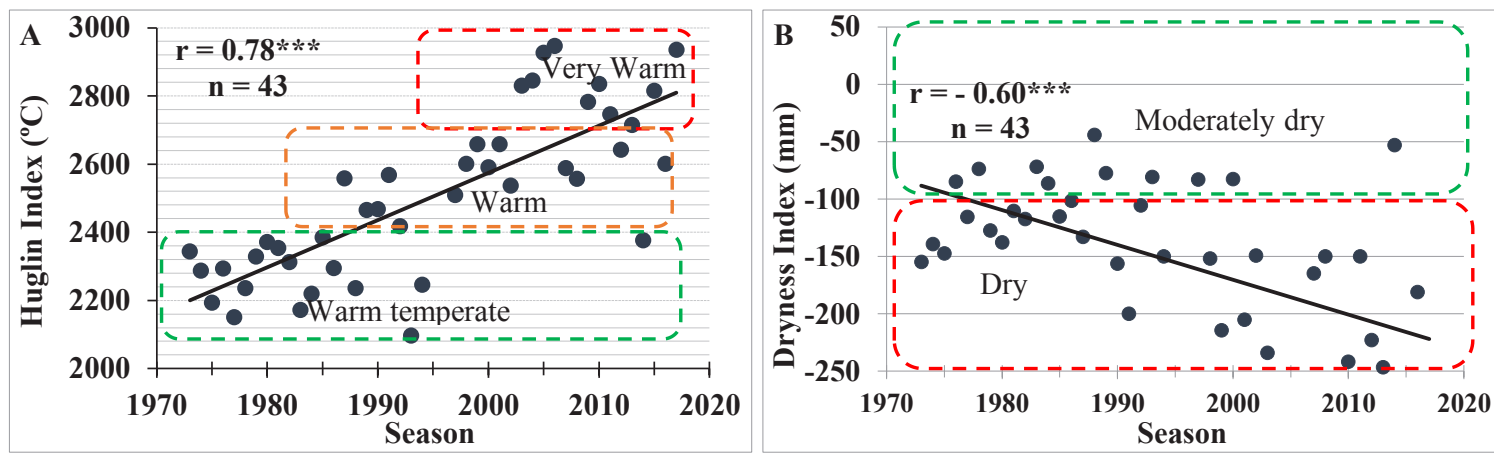

Figure 1. Evolution trend for the Huglin Index (A) and Dryness Index (B) over a 45 year period (1973-2017), calculated using data from a weather station located at Évora. The dashed rectangles indicate de boundaries of the classes.

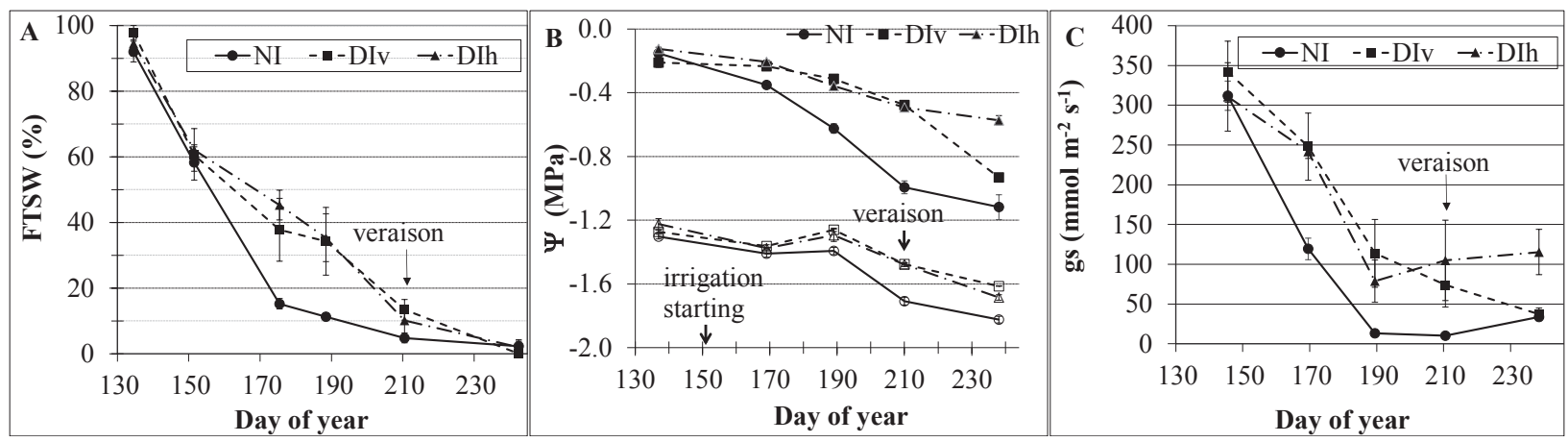

Figure 2. Seasonal pattern of the fraction of transpirable soil water (FTSW) (0-1.0 m) (A), predawn (close symbols) and midday (lower curves with open symbols) leaf water potential (B) and midday stomatal conductance (C) of cv Aragonez (syn.Tempranillo) vines subjected to different irrigation water supply and measured at the end of each drying cycle following irrigation: NI- non-irrigated; DIv - 50\% ETc withheld after veraison, DIh - 50\% ETc supplied until harvest. Average \pm standard error of 4 access tubes (A) or 6 adult exposed leaves (B \& C).

In NI vines leaf senescence started prematurely and, at veraison, about $60 \%$ of main leaf area had already been lost. At harvest (end of August) while the most irrigated plants showed only $26 \%$ of defoliation, NI vines presented $72 \%$. In DIv treatment the irrigation cut-off at veraison induced also a fast increase in leaf senescence, which attained at harvest a similar value to that of NI vines (Fig. 3A). The high rate of defoliation observed in NI vines induced a higher interception of PAR in the cluster zone than the two irrigated treatments. The irrigated treatments showed similar values of intercepted PAR until mid-ripening but at harvest DIv presented a higher value than DIh (Fig. 3B).

Due to a significantly lower berry and cluster weight, NI vines presented the significantly lowest yield, while DIh showed the highest one and DIv an intermediate value (Fig. 4). Regarding berry composition, no significant differences were observed except for the anthocyanins content, which was higher in NI vines as compared with the deficit irrigation treatments (Fig. 4). 


\subsection{Deficit irrigation at Reguengos de Monsaraz}

The seasonal trend of the FTSW measured in the experiment carried out at Reguengos is presented in Fig. $5 \mathrm{~A}$. Irrigation started middle of June enabling to almost refill the soil profile (60-80\%). In the second half of June

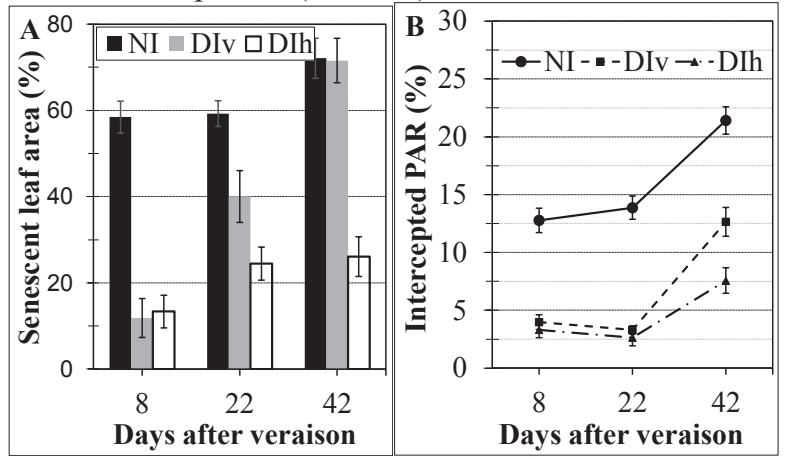

Figure 3. (A) Seasonal pattern of senescent leaf area (average $\pm \mathrm{SE}, \mathrm{n}=16$ shoots). (B) Photosynthetic active radiation (PAR, as percentage of the reference intercepted at the top of the canopy) intercepted at cluster zone (average of $40 \pm \mathrm{SE}$ measurements).

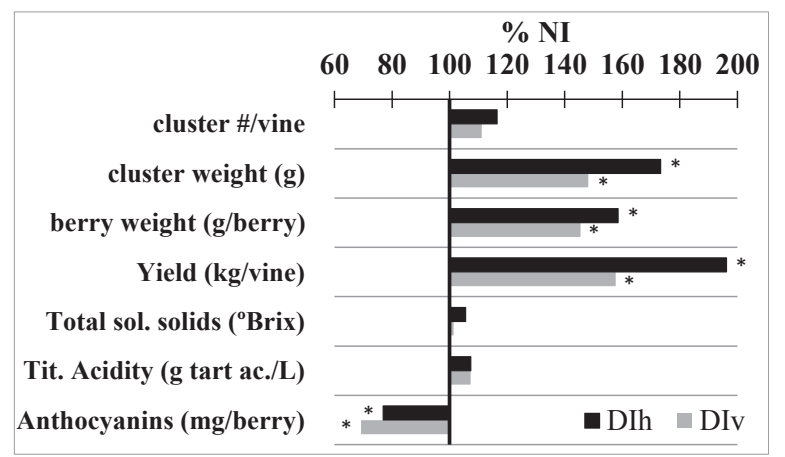

Figure 4. Yield and berry composition of 'Aragonez' (syn. 'Tempranillo') grapevines subjected to irrigation water supply. Values expressed in \% of the control NI vines. Asterisks indicate statistically significant differences from NI at $\mathrm{P}<0.05$ by LSD test. NI: nonirrigated; DIv: 50\% ETc withheld after veraison; DIh: $50 \%$ ETc supplied until harvest.

and July withholding irrigation in RDI induced a punctual strong decrease in FTSW as compared to SDI. After veraison (end of July) both irrigation treatments showed a similar trend but RDI presented lower FTSW after each irrigation event.

$\psi_{\text {pd }}$ presented a decreasing trend along the season in both irrigation treatments, with oscillations related to the several irrigation events (Fig. 5B ). After the first period of withholding irrigation in RDI, SDI started to show higher $\psi_{\text {pd }}$ values as compared to RDI and the largest differences were observed at ripening. While the lowest $\psi_{\mathrm{pd}}$ values observed in SDI were around $-0.5 \mathrm{MPa}$ (indicative of a mild to strong water stress), RDI attained significantly lower $\psi_{\text {pd }}$ values ( $c a-0.7 \mathrm{MPa}$ ), indicative of a strong to severe water stress [25]. During the ripening period $\psi_{\mathrm{m}}$ attained very low values (from -1.56 to -2.18 $\mathrm{MPa})$ but no significant differences were detected between treatments (data not shown). Regarding the effects of irrigation on gas exchange, in general RDI induced a significant reduction in gs and net assimilation rate [26]. Figure 5C presents an example of the gs diurnal trend in a very hot day of the ripening period, showing a decreasing pattern from early morning in both treatments, with SDI vines presenting always larger gs than RDI ones.

Deficit irrigation strategies promoted different water supply and influenced the ability of the canopy for evaporative cooling. As compared to SDI, RDI strategy induced a significant increase in canopy temperature as assessed by thermography [26]. Thermal data from individual leaf temperature assessed by thermocouples indicates also that the exposed leaves can achieve very high temperature during the day as shown in the example of Fig. 6A. The same figure also shows that at the hottest hours of the day, the west side of the canopy presents the highest leaf temperatures, which can achieve values higher than $10^{\circ} \mathrm{C}$ above air temperature $[8,26]$.

Berry temperature was also assessed with thermocouples installed in different cluster positions within the canopy and then related to berry composition (for more detailed data see [21]). Using berry temperature from berry pea-size to full maturation, the work of [21] showed that irrigation treatment has a slight effect on the temperature of berries from clusters at similar exposure. However, when comparing the maximum berry temperature per irrigation treatment, berries from west exposed clusters presented maximum temperatures 5 to 8 ${ }^{\circ} \mathrm{C}$ and 2.5 to $9{ }^{\circ} \mathrm{C}$ higher than those from east exposed clusters in SDI and RDI treatments, respectively. Consequently the berries from west exposed clusters accumulated a higher number of hours of temperature above $35^{\circ} \mathrm{C}$ than berries from east exposed clusters [21]. Figure $6 \mathrm{~B}$ presents an example of the daily evolution of exposed berries temperature during three hot days of the ripening period for RDI treatment, showing that from mid-morning to mid-afternoon the temperature of exposed berries (East and West) was above $35^{\circ} \mathrm{C}$ and that the highest temperatures were attained at the west exposed berries during the afternoon. As the westexposed berries displayed lower anthocyanin concentration than east-exposed berries, irrespective of irrigation (Fig. 6C), the same authors concluded that the higher number of heating hours could have a key role in anthocyanins biosynthesis repression and degradation.

We found no significant effect of irrigation strategy on vine vigor (data not shown). Irrigation has also no statistically significant effect on yield despite of a minor reduction $(16.5 \%)$ observed in RDI vines as compared to SDI ones.

\section{Discussion and conclusions}

In this work we have reviewed some ecophysiological and agronomical data obtained in two irrigation trials set up at the very hot and dry winegrowing region of Alentejo, located at inland south Portugal. In the last decades the temperature-based Index of Huglin showed a positive trend, while the Dryness Index presents a 
negative trend over time, indicating that the incidence of heat and drought stress at the Alentejo winegrowing region has increased in recent years. Results from the Évora experiment show that the rainfed vineyards cannot
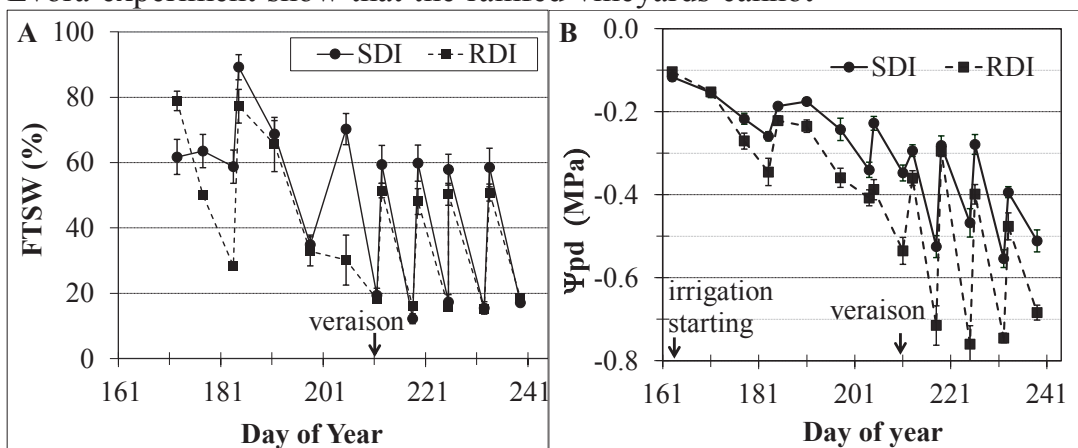

withstand severe drought stress as soil water reserves cannot support adequate transpiration inducing very early and severe water deficits.

Figure 5. Seasonal trend of the fraction of transpirable soil water (FTSW) (A), predawn leaf water potential (B) and daily course of stomatal conductance to water vapor (gs) measured in a warm day of the ripening phase (19 ${ }^{\text {th }}$ August 2013).

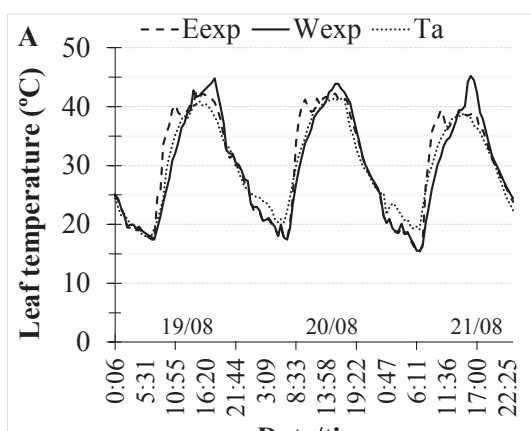

Date/time

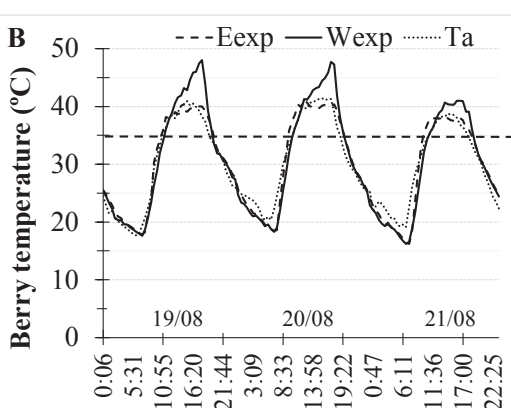

Date/time

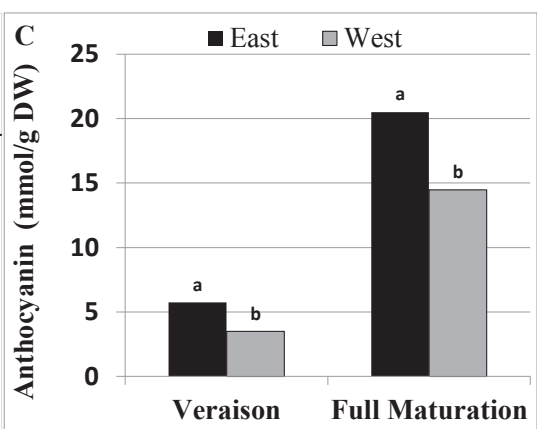

Figure 6. Hourly exposed leaf $(\mathrm{A})$ and berry $(\mathrm{B})$ temperature during 3 consecutive days of the ripening period (19 $9^{\text {th }}$ to 21th August). Eexp - East exposed; Wexp - West exposed; Ta - average air temperature. In plot B) the dashed horizontal line shows the berry temperature threshold above which anthocyanin biosynthesis could be compromised. The plot C) shows the averaged effect of canopy side (East $v s$ West) on anthocyanin accumulation in the grape berry skin of exposed clusters The bars with different letter suffixes indicate significant differences $(\mathrm{p}<0.05)$. Adapted from [21]).

As a response to soil drying decreased stomatal closure resulted in higher leaf temperature and promoted leaf senescent and leaf burning, especially in NI vines. Increased light penetration at the cluster zone due to leaf abscission, increased the fraction of exposed clusters which can be, in most temperate wine regions, beneficial to phenols and anthocyanins accumulation since this process is strongly light dependent [19]. However, the degree of cluster exposure influences berry temperature, which can block the synthesis of anthocyanins or induce their degradation $[20,27]$. Defoliated vines, like those of NI, are much more exposed to berry sunburn and/or experience the negative effects of the high temperature on berry ripening. However, surprisingly, the anthocyanin content was higher in NI berries than in the deficit irrigated ones results that can be explained by the positive effect of the smaller berry size (smaller berries would result in a higher skin/flesh ratio [28], which could have overridden the expected negative effect of high berry temperatures on anthocyanin biosynthesis.

In practical terms, Évora trials showed that deficit irrigation should be applied until harvest, as the irrigation cutoff at veraison has also induced a severe water stress and a strong leaf senescence during the ripening period.

The results from Reguengos experiment showed that the use of RDI allowed to save water, as compared to the conventional SDI used by the grower, without significant effects on yield. However, in this terroir it is very risky to reduce irrigation amounts behind a certain threshold as it can induce very stressful conditions during the ripening period. Indeed, the use of deficit irrigation strategies induced a progressive decrease in the FTSW along the growing season, which in the case of the RDI strategy, induced predawn values that are indicative of a strong to severe water stress [25]. As reported above, in these conditions the restriction in stomatal conductance and consequent decrease in the ability for energy dissipation may increase vine vulnerability to leaf burning $[8,16]$ mainly during heat waves, which are occurring with higher frequency and for longer periods [4]. Furthermore, the results obtained at the Reguengos trial show the negative impacts of excessive cluster exposure on berry composition and reinforce the need to promote basal leaf health during the whole ripening period in order to provide sun protection to the grapes and, consequently, avoid either the risk of sunburn and/or negative effects of excessive high berry temperature on anthocyanin concentration [19 - 21].

In order to face these challenges and mitigate the negative impact of more extreme weather conditions in South Portugal, short to long term adaptation measures must be adopted [8]. More efficient irrigation practices 
and more precise irrigation scheduling will help to save water, while minimizing the negative impacts of climate change on viticulture in South Mediterranean countries $[8,29,30]$. Optimized plant and soil water monitoring system, and improved decision support systems based on weather soil and plant data integrated in real time will enable the growers to better manage the irrigation and to be alerted for risky situations (e.g. lower soil water availability, heat events forecast, etc) when certain thresholds are attained [31].

Furthermore, the irrigation infrastructure should be able to deliver higher amounts of water than the ones estimated for deficit irrigation in order to allow to refill the soil profile before a forecasted heat wave. The vineyard training system and canopy management should also be chosen/adjusted in order to provide natural bunch shading particularly at the canopy side sun-exposed during the afternoon. Many other adaptations are possible, e.g. the use of drought resistant rootstocks and varieties, the choice of vineyard soils with higher water holding capacity, the use of more adequate soil management practices, the use of sun protection agents, etc. $[32$ - 34].

In conclusion, our results show that the winegrowers of Alentejo need to do a strong effort to adopt measures that can cope with climate change and improve the sustainability and quality of wine production in these hot and dry terroir.

\section{Acknowledgements}

This research received funding from the Portuguese project PAMAF I\&ED 2007 and by European Community's Seventh Framework Programme (FP7/2007-2013) under the grant agreement $\mathrm{n}^{\mathrm{o}}$ FP7311775 , project INNOVINE.

\section{References}

1. IPCC Climate Change 2013: The Physical Science Basis. I Contribution of Working Group I to the Fifth Assessment Report of the Intergovernmental Panel on Climate Change. Cambridge Univ. Press, UK (2013).

2. H. Fraga, A.C. Malheiro, J. Moutinho-Pereira, J.A. Santos, Int. J. Biometeorol., 57(6),909-925 (2013)

3. H. Shultz, Journal Wine Economics, 11(1), 181-200 (2016)

4. R.O. Teskey, T.M. Wertin, I. Bauweraerts, M Ameye, M.A. McGuire, K. Steppe, Plant Cell Environ., 38(9), 1699-1712 (2014).

5. H. Fraga, I. García de Cortázar Atauri, JA Santos, Agric.Water Manag., 196,66-74, (2018)

6. J.A. Santos, A.C. Malheiro, J.G. Pinto, G.V. Jones, Clim. Res., 51(1),89-103 (2012).

7. J.M. Costa, M. Vaz, J. Escalona, R. Egipto, C. Lopes, H. Medrano, M.M. Chaves, Agr. Water Manage, 164,5-18. (2016).

8. IVV, Vinhos e Aguardentes de Portugal 2016. Instituto da Vinha e do Vinho, Lisboa. (2017).
9. M.M. Chaves, T.P. Santos, C.R. Souza, M.F. Ortuño, M.L. Rodrigues, C.M. Lopes, J.P. Maroco, J.S. Pereira, Ann Appl Biol., 150, 237-252 (2007).

10. P.R. Dry, B.R. Loveys, M.G. McCarthy, M. Stoll, J. Int. Sci. Vigne Vin, 35,129-139 (2001).

11. B.R. Loveys, M. Stoll, W.J. Davies, Water Use Efficiency in Plant Biology. Bacon M.A. (Eds.), University of Lancaster, Lancaster, UK, pp. 113-141. (2004).

12. T.P. Santos, C.M. Lopes, M.L. Rodrigues, C.R. Souza J.P. Maroco, J.S. Pereira, J.R. Silva, M.M. Chaves, Funct. Plant Biol., 30,663-671 (2003).

13. C.M. Lopes, T. Santos, A. Monteiro, M.L Rodrigues, J.M. Costa, M.M. Chaves, Scientia Horticulturae, 129,603-612 (2011).

14. K.C. Shellie, Am. J. Enol. Vitic., 65,197-205 (2014)

15. C.M. Lopes, M.L. Rodrigues, T. Santos, J. VicentePaulo, MM Chaves, Proc. Congres on Climate and Viticulture, Centro Transferencia Agroalimentaria, Saragoza, 10-14 April 2007: 87-92 (2007)

16. M.M. Chaves, J.M. Costa, O. Zarrouk, C. Pinheiro, C.M. Lopes, J.S. Pereira, Plant Sci., 251,54-64 (2016)

17. S.F. Price, P.J. Breen, M. Valladao, B.T. Watson. Am. J. Enol. Vitic., 46:187-194 (1995).

18. A. Belancic, E. Agosin, A. Ibacache, E. Bordeu, R. Baumes, A. Razungles, et al. Am. J. Enol. Vitic., 48,181-186 (1997).

19. L. Haselgrove, D. Bottingvan, H.P.B. van Heeswijck, P.R. Dry, C. Ford, P.G. Iland, Aust. J. Grape Wine Res., 6,141-149 (2000).

20. S.E. Spayd, J.M. Tarara, D.L. Mee, J.C. Ferguson, Am. J. Enol. Vitic., 53,171-182 (2002).

21. O. Zarrouk, C. Brunetti, R. Egipt, C. Pinheiro, T. Genebra, A. Gori, C.M. Lopes, M. Tattini, M.M. Chaves, Frontiers in Plant Science, 7,1-18 (2016).

22. A. Pellegrino, E. Lebon, M. Voltz, J. Wery, Plant Soil 266,129-142 (2004).

23. G.V. Jones, A.A. Duff, A. Hall, J.W. Myers, Am. J. Enol.Vitic., 61,313-326 (2010).

24. J. Tonietto, A. Carbonneau, Agr. Forest Meteorol., 124,81-97 (2004).

25. H. Ojeda, C. Andary, E. Kraeva, A. Carbonneau, A. Deloire, Am. J. Enol. Vitic., 53, 261-267 (2002)

26. I.F. García-Tejero, J.M. Costa, R. Egipto, V.H. Durán-Zuazo, R.S.N. Lima, C.M. Lopes, M.M. Chaves. Agric. Water Manag., 176, 80-90 (2016).

27. J. Bergqvist, N. Dokoozlian, N. Ebisuda, Am. J. Enol. Vitic., 52(1), 1-7 (2001).

28. R.L. Wample, R. Smithyman, Deficit Irrigation Practices. FAO (Eds.), Rome, pp. 89-100 (2002)

29. M.M. Chaves, O. Zarrouk, R. Francisco, J.M. Costa, T. Santos, A.P. Regalado, M.L. Rodrigues, C.M. Lopes, Ann Bot. 105, 661-676 (2010).

30. H. Medrano, M. Tomás, S. Martorell, J.M. Escalona, A. Pou, S. Fuentes, J. Bota, Agron. Sust. Dev. 1-19 (2014).

31. R. Egipto, A. Barriguinha, J. · Silvestre, N. Carvalho, M. Neto, J.M. Costa, C.M. Lopes, Actas 10. Simpósio de Vitivinicultura do Alentejo, pp. 57-61 (2016).

32. A. Palliotti, S. Tombesi, O. Silvestroni, V. Lanari, M. Gatti, S. Poni, Sci. Hortic., 178, 43-54 (2014). 
33. M.R. Mozell, L. Thach, Wine Economics and Policy 3, 81-89 (2014).

34. J.M. Costa, R. Egipto, J. Silvestre, C.M. Lopes, M.M. Chaves Water scarcity and sustainable agriculture in semiarid environment: tools, strategies, and challenges for woody crops. Elsevier Inc. pp. 219-245 (2018). 